\title{
Vicente Ignacio Imperial Digueri y Trejo: ingeniero militar, marino, urbanista y arquitecto del siglo XVIII
}

\author{
JuAN TORREJON Chaves
}

Nacido en Orán el 28 de junio de 1745, fueron sus padres Ignacio Imperial Digueri, oriundo de Cartagena y destinado, a la sazón, como oficial en el Regimiento de Infantería de esta plaza norteafricana, donde alcanzó el grado de comandante de su segundo batallón - puesto que desempeñaba cuando ocurrió su muerte, el 5 de junio de 1769-, y Paula Trejo Monroy y Salcedo, natural de Badajoz, quien falleció con posterioridad a mayo de 1781 , posiblemente en la ciudad de Cartagena. Otros hijos del matrimonio fueron: Antonio, Juan Bautista —que se ordenó sacerdote del Orden de Mínimos de San Francisco de Paula-, Manuel, Luisa y Teresa.

En agosto de 1761, cuando el joven Vicente Ignacio contaba 16 años, entró a servir de cadete en una de las compañías de Granaderos de la guarnición de Orán, participando en varias escaramuzas con los moros fronterizos. Posteriormente, efectuó en su Real Academia el Curso de Matemáticas, que concluyó en 1765, ingresando así en el Cuerpo de Ingenieros. En éste se graduó de subteniente - "delineador"-- y teniente - "extraordinario"-, ocupando destinos en obras diversas en Barcelona, San Fernando de Figueras y Cartagena; dedicándose en la ciudad departamental al proyecto de su fortificación, levantando plano general de 
todas sus inmediaciones, y a la construcción de las gradas de jabeques en el Real Arsenal ${ }^{1}$.

En 1774 pasó al Cuerpo General de la Armada con el empleo de alférez de navío y antigüedad de 5 de diciembre de 1770, fecha en la que obtuvo el de ingeniero extraordinario en el Ejército. Embarcado en la fragata "Clara», participó en los auxilios que se prestaron a Melilla, sitiada en los meses finales de 1774 y primeros de 1775 . El 15 de mayo de este año transbordó al navío "Velasco" como ayudante del teniente general Pedro de Castejón, con destino a la expedición de Argel, acción bélica en la que participó en el reconocimiento de las baterías enemigas, y en las actividades que se llevaron a cabo para demolerlas desde los buques; siendo comisionado para tratar con el general del ejército oponente. Concluida la desdichada expedición, entró en Alicante, pasando a bordo de la fragata "Santa Marta", con destino a recorrer los Presidios Menores y levantar el plano de las Islas Chafarinas, bajo las órdenes directas del entonces capitán de fragata y gran cartógrafo marítimo Vicente Tofiño de San Miguel.

A principios de 1776 pasó a la Corte bajo la dependencia inmediata del Secretario de Estado y del Despacho Universal de Marina, el ya Marqués de González de Castejón; puesto en el que obtuvo el grado de teniente de fragata en marzo del mismo año, y en el que permaneció hasta el día 31 de agosto siguiente, cuando fue nombrado ayudante del Mayor General de Cartagena. Aquí ejerció de Mayor por enfermedad del titular, desempeñando el importante cometido de poner el Cuerpo de Brigadas de su Departamento al pie del Real reglamento por entonces vigente. Ascendió a teniente de navio en febrero de 1777, embarcando tres meses más tarde en la goleta "San Antonio", para mandar una escuadra de cuatro, con destino a hacer el corso contra los argelinos, desde Cartagena al cabo de Creus. Concluida esta comisión, desembarcó en Cartagena, incorporándose a Batallones como capitán de la tercera compañía del noveno, con la que se trasladó, el 3 de julio del 78 , al navío "San Nicolás" para guarnecerlo; pasando éste a integrarse en

\footnotetext{
Su biografia la he podido componer a partir de los expedientes personales que se conservan en el Archivo General de Marina (en adelante, $A A B$ ) "Don Álvaro de Bazán" (Viso del Marqués, provincia de Ciudad Real), y en el Archivo General Militar (Segovia). En el primero, se halla su hoja de servicios en la Armada y la RO por la que ingresó en ella sin tener que pasar por los empleos de guardiamarina y alférez de fragata, expedida en San Ildefonso el 18 de agosto de 1774, firmada por Julián de Arriaga, y dirigido al Director General de la Armada. Andrés Reggio; en el segundo, se encuentra el expediente matrimonial para casar en primeras nupcias (leg. D-831).
} 
la escuadra surta en Cádiz, lugar donde se hallaba en marzo de 1779. El día 9 de este mes le fue comunicada a Imperial Digueri la Real resolución por la que debía encargarse de la dirección de las obras de la nueva población para la Armada en la Isla de León, una vez que se había decidido separar enteramente de estas actividades a los ingenieros del Ejército en ellas delegados, pertenecientes a la Dirección y Comandancia de "Caminos, Puentes, edificios de Arquitectura Civil, y Canales de riego y navegación", al frente de la cual se encontraba el arquitecto italiano Francisco Sabatini. En las prevenciones que se le hicieron desde la Secretaria de Estado de Marina, destacan:

1. Que debía proseguir las obras con arreglo al plano empezado según las Reales disposiciones, y a las directrices ya aprobadas.

2. Que la empresa habría de verificarse en los mismos términos que las demás de Marina, en cuanto al régimen de su economía.

3. Que tendría que acudir para todo y en todo directamente a la Vía Reservada de la Secretaría de Marina, desde donde se le darian las órdenes de lo que debiera practicarse.

4. Que se le facultaba para elegir al oficial de Marina que considerara más adecuado, a fin de que llevase el detall.

5. Que, con prontitud, se le auxiliaria con un arquitecto de obras de arsenales, para ser empleado bajo su mando.

6. Que se le autorizaba para quitar sobrestantes, maestros, y cuantos puestos tenian establecidos, hasta el momento, los ingenieros de Tierra.

7. Que se esperaba su más armoniosa colaboración con la Junta del Departamento, en los variados casos que pudiesen ocurrir; pues de tal cooperación, y de su personal celo y aplicación dependía el más pronto y acertado adelantamiento de tan útil y necesaria empresa ${ }^{2}$.

Realizó esta tarea durante diez años y dos meses, permaneciendo en la comisión hasta el 16 de mayo de 1789, momento en que se le confirió la Tenencia de Rey de la plaza de Tarragona.

2 Archivo General de Simancas (en adelante, AGS), Secretaría de Marina, leg. 361 : "Comunicaciones a la Junta del Departamento de Marina de Cádiz de la Real resolución de separar enteramente del encargo de las obras a los ingenieros del Ejército, quedando la comandancia de ellas en un teniente de navio de la Real Armada; y al teniente de navio Ignacio Digueri, nombrándosele comandante de las obras de la Nueva Población en la Isla de León". 
En orden a su carrera militar y a su vida privada, los hechos más destacados de este decenio (marzo 1779 / mayo 1789) fueron: 1780.

- El ascenso a capitán de fragata graduado, el 20 de mayo de

- La obtención de la licencia matrimonial para casar con Juana Nepomucena María de la Riva, el 16 de junio de 1781. (Ésta era hija de Manuel de la Riva - Comisario Real de Guerra y Contador General de Indias-, ya fallecido; y de María Baso, residente entonces en Nueva España. Juana Nepomucena casó en primeras nupcias, a finales de 1774 , con Juan Arturo, alférez de navio y teniente de la quinta compañía del undécimo batallón de Marina, quien pereció en el incendio del navío "Santo Domingo", ocurrido el 16 de enero de 1780 , en el combate que sostuvo con los de la Gran Bretaña).

- La promoción a capitán de fragata el 21 de diciembre de 1782.

- El nombramiento de capitán de navío e ingeniero en jefe de Marina, el 15 de noviembre de 1784, y su posterior inclusión como vocal de la Junta departamental de Cádiz (R.O. de 23 de noviembre de 1784).

- La Real concesión, en abril de 1787, a consulta del Consejo de Guerra, de la licencia para casar en segundo matrimonio con María Ana Rodríguez de Arias. (Sobre su descendencia, documentalmente se advierte, en 1798, acerca de su "dilatada familia»).

En diciembre de 1790 cesó en su destino tarragonés, reintegrándose al servicio activo de la Armada. Se encontró, en 1793, en la reconquista de las islas de San Pedro y San Antíoco en Cerdeña, y en el apresamiento de la fragata de guerra francesa "Hélène" en el golfo de Palma. En julio de 1794 volvió al Departamento de Cádiz para encargarse de la Comandancia del Arsenal de La Carraca, que desempeñó hasta agosto del 98; siendo de advertir que ocupó, además, la Subinspección del mismo establecimiento, reunida a aquella desde el 3 de abril de 1796 hasta el 22 de enero de 1798. De su actividad aquí, se ha de destacar la acreditada en los navíos de la escuadra de José de Mazarredo, quien en abril del 97 -dos meses después del desastre naval del cabo San Vicente- se hizo cargo de la Comandancia General de la Armada del Océano.

Fueron, precisamente, estas circunstancias tan críticas, unidas al buen desempeño de sus funciones, las que motivaron que, en junio de 1797, se le prorrogara por otros tres años en la Comandancia del Real Arsenal. Pero, saliendo en la tarde del 26 de agosto de 98 del navío "Concepción", al que habia acudido para disponer su entrada en dique, 
dio una caída al saltar del barco a su bote, pegando de espaldas con la cabeza sobre una regala. Inhabilitándose con ello para continuar en tal comandancia, hubo de solicitar la dimisión, que le fue concedida. (En el momento de ocurrir el accidente, su salud se hallaba muy quebrantada; pues el verano había representado para él una época de indisposición continuada padeciendo repetidos cólicos y diarreas). Desde esta última fecha hasta el 5 de noviembre de 1805 -momento en el que terminó su carrera en la Marina, concediéndosele el pase a Ingenieros del Ejército con el grado de coronel, al tiempo que se le nombraba brigadier de Infantería y era destinado a la Comandancia de Ingenieros de Cartagena- se ocupó en comisiones de más relajada actividad, tales como la Inspección de las Revistas de Matrículas del Departamento de Cádiz, su Comandancia Militar de Marina, Juez de Prófugos... Destacando la presidencia del Consejo de Guerra, que se formó en el mismo Departamento para juzgar a los reos indiciados de robo en el Real Arsenal, y de la quema de su fábrica de jarcia; hechos que acontecieron en mayo de 1802.

Su fallecimiento ocurrió con posterioridad a junio de 1816, posiblemente en Cartagena. En su historial, deducido de las listas maestras donde se le estamparon sus servicios contraidos en el Cuerpo de la Armada, consta que ninguna nota ni tacha desfavorable le hizo desmerecer del buen concepto que adquirió por su siempre recto proceder y conducta irreprensible. En el informe que el Marqués de Casa-Tilly envió a la Secretaría de Estado de Marina, con motivo de haberse producido la vacante de la Comandancia del arsenal de La Carraca, se encuentra una breve descripción de sus cualidades. Recomendándolo en primer lugar para el puesto -que le sería concedido-, dice de él:

«Dn. Vicente Ignacio Imperial Digueri... Es oficial de conducta, valor conocido, talento despejado, muy activo, con mucho método e inteligencia en el ramo de Ingenieros, como tiene acreditado en las comisiones que ha tenido" ${ }^{3}$.

Representativo en el mayor grado fue el momento que Imperial Digueri escogió para abandonar la Armada de manera definitiva, escasos

3 AAB, Arsenales-Construcciones, leg. correspondiente al año 1794: «Propuestas del Marqués de Casa-Tilly a la Secretaría de Estado de Marina para ocupar el destino de Comandante del RI. Arsenal de La Carraca, ante la vacante producida por haber conferido S. M. el mando del navio "Triunfante" a D. Vicente Yáñez". 
días después del combate de Trafalgar (21-X-1805). Resulta verosímil pensar que, con la perdida batalla naval —obligado colofón a la prolongada serie de yerros que se sucedieron, desde la salida del bailío Antonio Valdés y Bazán de la Secretaría de Estado de Marina, el 13 de noviembre de 1795- aquél viese que se ahogaban definitivamente sus esperanzas de ascender a brigadier de Marina, según le habian anunciado en la ya lejana y significativa fecha del 14 de julio de 1789 , sin haberse llevado a efecto. Imaginando, pues, que no seguiría a la Armada otro estado que el de la postración tras la nefasta derrota, se reintegró al Real Cuerpo de Ingenieros del Ejército, del que había estado ausente por espacio de 31 años.

Variadas fueron las razones que movieron el ánimo del Marqués de González de Castejón para elegir a Imperial Digueri director de las reales obras en la Isla de León. Una vez que ocurrió el durísimo enfrentamiento entre los ingenieros del Ejército, comisionados por Sabatini, y la Junta del Departamento de Marina, en su Secretaría de Estado existió la firme resolución de eliminar cualquier elemento extraño a la Armada de la intervención de estos trabajos, colocándolos bajo un control exclusivo. No obstante ello, se precisaba que la nueva dirección recayera en un marino - sujeto directamente, por lo tanto, a la escala de mando del Departamento-, pero con conocimientos y experiencias en el campo de la ingeniería. Además, el propio Secretario de Estado deseaba controlar personalmente el progreso de estas actividades, para lo cual necesitaba colocar a su frente a un individuo de su entera confianza. En conclusión, se requería un miembro de la Armada con formación y práctica de ingeniero, de quien pudiera fiarse cabalmente el propio Secretario de Estado y del Despacho Universal de Marina. El perfil del candidato coincidia, con precisión extraordinaria, con Imperial Digueri y la trayectoria que habia seguido: otrora ingeniero de Tierra, marino entonces, que había servido por dos veces a las órdenes directas de González de Castejón.

En su larga gestión de diez años como director del magno empeño carolino, se deben distinguir dos períodos consecutivos y nítidamente diferenciados: el primero, cerrado a finales de 1784, se caracterizó exclusivamente por la continuidad del desmonte, terraplenado y acopio de los materiales resultantes de los terrenos donde habría de levantarse la nueva población para la Armada, siguiendo los proyectos de Sabatini; el segundo, hasta mayo de 1789 — cuando abandonará la dirección de la empresa-, se singularizó por ser un momento más personal y creativo, prosiguiendo el desmonte hasta su total conclusión en mayo de 1778, diseñando un interesantísimo programa urbanístico, substitutivo del concebido por el arquitecto italiano, y trazando los planos particulares de dos 
Vicente Ignacio Imperial Digueri y Trejo: ingeniero militar, marino...

de los edificios reales en él previstos: el Cuartel de Batallones y la Iglesia Parroquial de la Purísima Concepción, hoy Panteón de Marinos llustres.

La fecha del inicio de la segunda fase referida vino impuesta por la finalización de la guerra contra la Gran Bretaña (junio de 1799 - septiembre de 1783), conflicto éste que abrió una etapa de conflagraciones especialmente onerosas, que significaron el punto de arranque de la quiebra de la hacienda del Antiguo Régimen. El fin de las hostilidades iniciadas en el 79, y la consiguiente reapertura de las comunicaciones con América, crearon una coyuntura económica favorable, incidiendo en una feliz reactivación de las labores en la nueva población para la Armada en la Isla de León. Aquí los efectos de la contienda se habian hecho notar extraordinariamente, ya que las urgencias bélicas hicieron depender las consignaciones para las obras de otras prioridades en el Departamento de Marina; llegando a representar el decurso de las hostilidades una durísima prueba de fuego en el progreso de las labores, cuyas dificultades fueron sorteadas de manera harto tenaz y pragmática por Imperial Digueri.

Tras los gastos de desmovilización y desarme de las escuadras, y una vez liberada la Secretaría de Estado de Marina de los continuos objetos de atención preferente que la guerra habia impuesto, se decidió reemprender con actividad los trabajos en la Isla de León, para lo cual se dispuso un conjunto de providencias por R.O. de 23 de noviembre de $1784^{4}$, de efectos fundamentales en la marcha de tan importante empeño. Entre las nuevas medidas a tomar, la de mayor trascendencia fue la de apartar el proyecto urbanístico de Sabatini, aprobado en 1777, y reemplazarlo por otro de nueva creación, a realizar por el director de las obras; variando la situación de la nueva población, que debía ser retirada 100 varas en dirección al caserío viejo de la Isla, con el objeto de buscar más terrenos en firme, evitando así los de la albina, de considerables gastos en el proceso constructivo, ya que obligaban a pilotar, envarengar y encallar para hacer la cimentación de los edificios. El nuevo proyecto debía contar con los siguientes edificios reales: Iglesia parroquial, Casas de la Dirección General, Intendencia y Oficios Principales, Cuartel y Academia de Guardias Marinas, Academia de Pilotos, dos Cuarteles para los Batallones, Cuartel con Academia para el RI. Cuerpo de Artillería, y Hospital.

En febrero de 1785 comenzó Imperial Digueri a elaborar los planos, vistas y perfiles del nuevo proyecto general, recabando las oportunas

4 Ibidem, leg. concerniente al año 1784 . 
noticias acerca del número de individuos, estancias y demás circunstancias a que debiera arreglarse cada uno de los edificios públicos previstos; contando en tal actividad con la valiosísima ayuda del arquitecto formado en la Real Academia de San Fernando, Antonio de Bada y Navajas. Exactamente un año más tarde, el 21 de febrero de 1786, el director de las obras pasó a manos del entonces Capitán General del Departamento, Luis de Córdoba, para los fines que preveía el artículo 586 de la Real Ordenanza de Arsenales, los diseños que había formado.

El nuevo proyecto urbanístico (Plano I) ${ }^{5}$ conforma un amplio rectángulo de 900 varas de largo y 650 de ancho, con una superficie total de 585.000 varas cuadradas, que alberga una variadísima gama de manzanas, todas regulares y rectangulares, con trece modelos diferentes, destinadas nueve de ellas a ser ocupadas por edificios públicos y 57 para las construcciones de los particulares.

Se trata del paralelogramo citado por Antonio Ponz en su Viaje de España ${ }^{6}$, quien deliberadamente calla el nombre del diseñador, cuidándose de dar noticias de Sabatini como autor del primer proyecto - al que erróneamente atribuye la planta de un pentágono- (Plano II) ${ }^{7}$, y de su

5 Museo Naval de Madrid - con posterioridad, MNM-, Cartoteca, sig. 2A-7: «Plano de la nueva Población en que resulta su Planta con arreglo a las Rs. Ordenes de 23 de noviembre del año pasado, 11 de febrero del corriente, y Acuerdos de la Junta de este Departamento, con demostración de los terrenos que son de S. M., y los que se necesitan comprar". Firmado por Vicente Imperial Digueri en la Isla de León, el 18 de agosto de 1785. Con explicaciones y notas diversas.

Este plano I lo encontré inconexo en el Archivo General de Marina, siendo remitido al Museo Naval de Madrid en compañía de los planos III y IV del presente trabajo, para una más correcta conservación, una vez que los fui deslegajando en el proceso de investigación documental de mi tesis doctoral, titulada: "La Nueva Población de San Carlos en la Isla de León (1774-1806)".

6 A. Ponz, Viage de España, Madrid, Viuda de D. Joaquín Ibarra, 1972, Tomo XVII, Carta Sexta, pág. 308.

AGS, Secretaría de Marina, leg. 373 (sin catalogar): «Plano de la Nueva Población en que se manifiestan los Depósitos de Materiales acopiados por fin de el año de 1783". Firmado por Vicente Imperial Digueri en la Isla de León, el 31 de diciembre de 1783. Con explicaciones.

Representa el proyecto de Francisco Sabatini, sancionado por Carlos III el 21 de junio de 1777. Se trata de un poligono irregular de diez lados con una gran fachada marítima de 776 varas lineales, plaza mayor excéntrica y cuadrada — de 150 varas de lado-, plaza rectangular abierta al mar -150 × 95 varas -, trama urbana ordenada en forma de retícula ortogonal, variada gama de manzanas - todas cuadrilateras, con ocho modelos regulares y cuatro irregulares, destinándose las más amplias para la construcción de los edificios públicos-, calles con una misma y espaciosa anchura de 15 varas, etc. Detenidamente me he ocupado describiendo este programa en la tesis reseñada anteriormente y en el trabajo expuesto al III Congreso Histórico sobre "Nuevas Poblaciones", que tuvo lugar en La Carolina en octubre de 1988, bajo el epigrafe: "Francisco Sabatini y su proyecto de ciudad 
amigo el Marqués de Ureña, director a la sazón de las obras. Posiblemente el Secretario de la Real Academia de San Fernando creia resarcirse asi de la no admisión en la empresa, en septiembre de 1785, de dos recomendados suyos y de Isidro de Granja: los jóvenes arquitectos Bernardo Fernández del Anillo y Guillermo Casanova. Lo que, posiblemente, nunca llegara a saber el erudito viajero es que el bueno y siempre prudente de Imperial Digueri en nada fue responsable de la suspensión de tal elección. Sería Juan de Villanueva el que en un informe, algo malintencionado, al Secretario de Estado de Marina, Antonio Valdés y Bazán, puso en entredicho la suficiente cualificación de tales técnicos, ofreciéndose personalmente a visitar las obras en la Isla de León. Una vez esto efectuado, y después de tantear a quienes las asistían, procuraría buscar en Madrid los sujetos más adaptados, según las necesidades advertidas, con el fin de "establecer un buen método de construcción que no parece ser muy conocido por aquella tierra" ${ }^{8}$. Desafortunadamente, no se consideró conveniente la intervención del mayor de nuestros arquitectos del XVIII, que se encontraba en los momentos más fecundos de su actividad creadora. Así se desaprovechó la oportunidad de vincular de alguna manera a tan gran empeño la ingente personalidad de Villanueva. Aunque de manera fugacísima, la rutilante estrella vilanovista había proyectado sus rayos sobre la nueva población; y si la no menos brillante de Sabatini habia sido ya alejada, a ésta no se le permitió ni siquiera acercarse. Bien se aplicaba la Real Armada en tener el absoluto control de este proceso, emblemático del control espacial y de la nueva política centralizadora del momento: se trataba de la nueva Cádiz, respuesta ilustrada a la densificación del caserío gaditano, encorsetado por un conjunto de fortificaciones de primer orden, potenciado por el efecto inducido del desastre de La Habana de 1761. Reafirmada, pues,

maritima: la nueva población de la Isla de León".

Jordi Oliveras Samitier presentó una comunicación al segundo simposio de Urbanismo e Historia urbana, celebrado en la Universidad Complutense en febrero de 1982, titulado «El proyecto de Sabatini para la ciudad de San Carlos en la Isla de León y el ocaso de la ciudad renacentista" (véase: A. BONET CORREA coord., Urbanismo e Historia urbana en el mundo hispano, Madrid, Editorial de la Universidad Complutense, 1985, Tomo II, pág. 905916). Mi opinión al respecto es que atribuye al arquitecto italiano un conjunto de ideas bastante difusas sobre la posible organización de la ciudad, elaboradas en el seno de la Secretaria de Estado de Marina por el teniente general Pedro de Castejón, y que se pasaron a Sabatini para que realizara su programa.

\& AAB, Arsenales-Diques, leg. relativo al año 1785: “Comunicación de Juan de Villanueva a Julián de Retamosa, quien le preguntó de Orden el Excmo. Sr. B. ${ }^{\circ}$, sobre el juicio que le merecen Guillermo Casanova y Bernardo Fernández del Anillo; recomendando suspender su elección hasta que él visite las obras y compruebe las necesidades. Madrid, 29 de septiembre de 1785". 
la conciencia de gran ciudadela, de urbe cerrada, no quedaba para la gran ciudad atlántica otra opción que saltar la masa pétrea de sus murallas, proyectándose en otro punto de la bahía luminosa.

Trazada con un objetivo concreto, concebida desde la específica función militar-naval, definida la ciudad cualitativamente, el deseo del proyectista por armonizar su programa urbano con el entorno le llevó a trazar una serie de alamedas y paseos arbolados, que envuelven la nueva población por sus cuatro fachadas, desde donde parten los caminos de comunicación con Cádiz, la población vieja de la Isla de León, y el puente de Zuazo, conectando aquí con el arrecife real; confiriendo con ello al conjunto una sensación de coherencia y cerramiento (Plano III) ${ }^{9}$. El urbanista ha sentido la necesidad de definir, de acotar la ciudad, con un doble objeto: diferenciarla de la naturaleza circundante, destacando así la intervención sobre el territorio - mas poniendo en conformidad estas dos realidades tan diversas, a través del cambio gradual que representa el recinto arbolado, la naturaleza humanizada - y evitar la posible descomposición del programa ante la ausencia de límites precisos que propiciara un crecimiento desordenado, la ruptura de la regularidad de la planta. De este modo, los paseos con árboles sobrepasan en mucho sus cualidades utilitarias - sombra, frescor, regeneración del aire, cortavientos, amenidad...- para elevarse a la categoria de símbolo, de atributo acorde con una visión racionalista de la urbe, la naturaleza y el paisaje.

Además, este "cinturón verde», al mismo tiempo que marca los límites de la nueva población, reemplaza a las fortificaciones, que se substituyen por cuatro filas de árboles, dos bordeando la calzada principal para coches, y las otras dos flanqueando los senderos laterales para peatones, tal como pedía Patte en sus Memoires sur les objets les plus importants de l'architecture. Con ello, Imperial Digueri otorga al proyecto un carácter ambivalente, en cuanto representante de un equilibrado sincretismo entre la ciudad abierta y la ciudad cerrada. El oranés, pues, en línea con la corriente liberal que, a fines del siglo XVIII, empujaba hacia la ruptura de los recintos, se posiciona nítidamente en el dinamizador cambio que obvia la unidad de límite rigido, la urbe circunvalada por la muralla, tan ardientemente defendida por J. F. Sobry en su De l'architecture - «une ville sans mur n'est une ville»- y en la Poetique des arts - «en

9 MNM, Cartoteca, sig. 2A-9: "Plano de la Nueva Población de San Carlos y de los terrenos de particulares contiguos a los de S. M.". Firmado por Vicente Imperial Digueri en la Isla de León, el 14 de marzo de 1788. Con explicaciones. 
passant soux les linteaux de la porte d'un ville, on sent qu'on se soumet a ses lois"-.

El afán del diseñador por diferenciar con nitidez lo propio de lo ajeno, le lleva a señalar una línea divisoria, término del crecimiento desaforado de la vieja población de la Isla, que se acercaba inexorable y amenazante hacia los terrenos del Rey; destinándose una amplia franja de terreno como «tierra de nadie", que serviria para desahogo y aireación de ambos núcleos urbanos. En la prolongación del eje vertical-central, Imperial Digueri sitúa una interesante calle de comunicación que enlaza la población por él planificada con la de la Isla de León, para una mayor comodidad de relación entre sus respectivos habitantes, diseñando incluso los edificios que habrían de conformar las ocho manzanas que la componen, de dos cuerpos y sobre pórticos (Plano IV) ${ }^{10}$. Significativos son los gráciles remates que, a modo de almenas, coronan estas fachadas, en forma de prisma cuadrangular y culminados por una bola de barro vidriado, tan del gusto del barroco popular de la arquitectura isleña; ornato mezquino y extravagante para el estricto criterio de Antonio Ponz, a quien parecieron cosa no arreglada a las verdaderas reglas del arte, ofendiendo la vista de todo hombre de gusto.

Por R.O. de 14 de marzo de 1786 se aprobó el diseño general de la nueva población para la Armada en el Departamento de Cádiz, determinándose que el pueblo tomara "el glorioso nombre de San Carlos en memoria de su Augusto Fundador el Sr. D. Carlos III, que felizmente reina" "1; previniéndose al Capitán y Director General con el fin de que la Junta, por él presidida, facilitara todos los auxilios necesarios para conseguir el mayor adelantamiento de la Real empresa, conscientes sus inspiradores de que este programa unitario de primer orden, innegable paradigma de urbe dieciochesca, era el más ambicioso de los proyectos poblacionales de la España carolina.

En los nuevos planes figuraban dos cuarteles capaces de albergar, entre ambos, cuatro batallones de Marina. $Y$ era tan apremiante la ne-

10 Ibídem, sig. 2A-1: "Vista de una manzana de las que se proponen en los terrenos del Marqués de Casa Alta y en la Calle de Comunicación". Firmado por Vicente Imperial Digueri en la Isla de León, el 14 de marzo de 1788.

"AAB, Arsenales-Construcciones, leg. perteneciente al año 1786: «R. orn. relativa a los terminos en que S. M. se ha servido aprobar los planos, y proyecto de la nueva Población". En la resolución se expresaba la satisfacción que en la Secretaria de Estado de Marina producian el celo y la aplicación del ingeniero en jefe, asi como el trabajo de delineación ejecutado por el arquitecto Antonio de Bada y Navajas, a quien el Rey se servía conferirle el grado de alférez de navio con el sueldo de 100 escudos mensuales. 
cesidad de contar con uno de ellos, al menos, que el ingeniero-comandante presentó, en diciembre de $1785 \mathrm{y}$, antes de efectuarlo con las trazas generales de la población, los planos, perfiles, vistas y presupuestos de un cuartel para dos batallones. Imperial Digueri lo concibió ocupando en su totalidad un enorme rectángulo de 134 varas castellanas de frente y 174 de costado, proporciones correspondientes con una de las dos manzanas más extensas - 23.316 varas superficiales- del proyecto general. Dos módulos adosados componen el conjunto: su frente, que contiene un pórtico de once arcos, con 40 varas de su fondo, se destina a pabellones de oficiales y plana mayor; contiguamente, un cuadrado de 134 varas de lado alberga los alojamientos de las doce compañías de los dos batallones - 2.016 soldados- en derredor de un soberbio patio ochavado circundado por galerías de 48 arcos. En síntesis, se trata de una de las más notables manifestaciones de la arquitectura militar española de finales del siglo XVIII, que goza de un claro precedente inmediato en su homónimo de la ciudad de Ferrol, existiendo un claro nexo que vinculó ambos cuarteles: el arquitecto Antonio de Bada y Navajas, quien trabajó en el arsenal del norte entre los años 1764 y 1779, trasladándose seguidamente a la Isla de León, donde se significó como el más firme sostén de Imperial Digueri durante su comisión en estas obras ${ }^{12}$. El proceso constructivo del Cuartel de Batallones de la nueva población de San Carlos abarcó desde junio de 1786, momento en el que se inició la apertura de sus inmensos cimientos -20.000 varas cúbicas-, hasta la conclusión del año 1803. Su diseñador lo dejó levantado a una altura general de 7 varas, continuando su erección el Marqués de Ureña. El noble y erudito gaditano introdujo importantes variaciones en los planes primigenios, siendo la más destacada la supresión de la galeria superior del gran patio achaflanado, que fue substituida por una azotea corrida con antepecho sobre la arcada del segundo cuerpo.

Acompañaron al programa general de la nueva población, los planos y presupuestos de la Iglesia parroquial, cuyos borradores fueron examinados por Julián Sánchez Bort, en aquel tiempo ocupado en la construcción del primero de los diques de carenar en seco de La Carraca, aprobándolos poco antes de su muerte. También contó el director-comandante con los importantísimos auxilios de su jefe del detall, el ya citado Antonio Bada y Navajas, y de su maestro mayor, el conocido José Prat,

12 Sobre el Cuartel de Batallones de la ciudad de Ferrol, conocido actualmente con el nombre de Cuartel de Nuestra Señora de los Dolores, véase: A. Vigo Trasancos, Arquitectura y urbanismo en el Ferrol del siglo xvill, Santiago de Compostela, Colexio Oficial de Arquitectos de Galicia, 1984, pág. 174-184. 
académico de mérito por la Real de San Fernando; sin cuyas asistencias resultaria difícil explicar las peculiaridades artísticas de este edificio barroco-clasicista. Haciendo acto de presencia, así, a través de sus discípulos, la sombra alargada del omnipresente Ventura Rodríguez.

Acerca del proyecto, su autor advertía que había intentado conciliar la grandiosidad con la sencillez, significando que el orden corintio que enriquecia la fachada y el interior no podía hacerse menos costoso, al no emplearse más cantería que la muy precisa. Ya que, aunque se proponia alguna de Málaga, Jerez y Tarifa, se economizaba al utilizarse tan sólo en basamentos, pilastras, fajas, cornisas y otros indispensables ornamentos; siendo todo lo demás de su fábrica, cantos, piedra quebrada y arena de lo producido por el desmonte, que se cubririan primorosamente de revoques y yeserías.

Presentándolo como uno de los objetos más recomendables de esta obra, el proyectista concibió un espacioso panteón subterráneo, que ocupaba el mismo ámbito bajo el pavimento de la iglesia; justificando su considerable desembolso de 1.015 .250 reales de vellón atendiendo a las ventajas que de su existencia resultarian, mas ofreciendo la posibilidad de trocarlo por cementerio alejado de la población, y en paraje adecuado donde los vientos generales no le perjudicasen. Con la existencia del panteón subterráneo, el ingeniero de Marina se apartaba del uso general - «bárbara y nociva costumbre", en expresión de Jovellanos- de dar sepultura a los cadáveres en los templos a la vista de todos; dando un paso más en la línea del progreso en esta materia ofreciendo echar fuera los enterramientos, alineándose así con los espíritus más avanzados del momento, opositores a una opinión generalizada, dominada por la rutina y la ignorancia, que creía en una mayor protección divina al ubicar los restos de los fallecidos al amparo de las iglesias. Que la idea de sacar los cadáveres de los poblados no había calado suficientemente entre aquellos sujetos que, en función de los puestos que ostentaban quedaban obligados a alejarse de los prejuicios de una sociedad aletargada, lo pone de manifiesto el dictamen de la Junta del Departamento al adoptar la solución representada por el panteón subterráneo y no recomendar la erección del cementerio exterior «para que no se toque la consecuente necesidad de los mayores gastos del cementerio fuera de poblado, con la indispensable urgencia de conducir los cadáveres a la distancia que se sitúe, tal vez sin el respeto y consideración debida en tales casos" ${ }^{13}$.

13 AAB, Arsenales-Construcciones, leg. del año 1786: «Acuerdo de la Junta del Departamento de Cádiz sobre el proyecto de la Iglesia, presentado por Digueri". Isla de León, 22 de febrero de 1786 . 
Felizmente, desde la Corte - factor de renovación en tantos aspectosse dio aprobación al proyecto de la iglesia, suprimido el panteón, que habría de substituirse por el cementerio situado fuera de la nueva población.

Imperial Digueri concibió el edificio sacro ocupando en su totalidad una de las manzanas del proyecto urbanístico de 1786, de $104 \times 40$ varas -4.160 superficiales-, cruzada longitudinal y simétricamente por su eje perpendicular-central, como edificio aislado con calles en su contorno, y la noble plaza mayor enfrente de su fachada principal. Ésta se encuentra formada por tres volúmenes, de los cuales el central, correspondiente a la portada, se encuentra adelantado y decorado por cuatro colosales columnas casi exentas de orden corintio, con cornisamento alineado con el exterior y frontón encima. Los laterales, no avanzados, se adornan con pilastras corintias, y debian haber sido coronados con torres campanarios, también con pilastras del mismo orden. El nexo entre el cuerpo avanzado y los extremos se resuelve con dos porciones de círculos en los que se abren puertas secundarias. Solución más audaz que la aplicada por Sánchez Bort en la Iglesia de San Julián, en el Ferrol, donde adelantó el plano de la fachada sobre las torres. Los vanos entre pilastras y columnas se ocupan con un orden subalterno compuesto poco resaltado, con formeros encima, iguales al arco del ingreso principal. En los claros de los formeros quedan claraboyas, y sobre sus arquivoltas ventanas a la francesa, con antepechos de hierro forjado. El proyecto original - cuyos planos fueron primorosamente delineados por Bada y Navajas, desgraciadamente, hoy perdidos - contemplaba en su lugar balcones con grandes ménsulas y ventana sobre el arco principal del ingreso.

El vestíbulo es de planta elíptica con cúpula y decoración de orden compuesto, con tres ingresos al interior del templo, correspondientes a las tres puertas de la fachada; situándose a la derecha el baptisterio, de planta circular y cornisa corintia, cubierto con cúpula. A la izquierda queda el acceso a la escalera de las previstas torres.

El interior del templo es de tres naves con pilastras de orden corintio. La nave del medio tiene 12 varas de ancho, 16 de alto desde el suelo a la cornisa, y 9 desde ésta a la bóveda. Sobre el anillo del crucero se debía haber elevado tambor sobre pechinas de orden romano con cúpula de medio limón de 18 varas de diámetro exterior y linterna de 3 , hasta alcanzarse las 68 varas de altura sobre el nivel del terreno.

El zócalo interior es todo él de mármol rojizo de Málaga, como todas las jambas $y$ dinteles de las puertas, con algunos ornatos de mármol 
Vicente Ignacio Imperial Digueri y Trejo: ingeniero militar, marino...

blanco de buena calidad. El altar mayor hubiera debido reducirse a una imitación del de la Capilla Real de San Isidro de Madrid, situándose detrás el presbiterio; y en el testero, ubicarse la sillería del coro y la tribuna del organo con balaustradas sobre ménsulas, sostenidas de modillones, artesonados con rosetones.

A espaldas de las capillas colaterales del lado de la epístola y del evangelio, que hacen frente a sus respectivas naves, quedan las sacristias, de planta circular, con ocho compartimentos cada una, exornadas de otras tantas columnas exentas de orden jónico que sostienen el anillo y la cúpula. Los capiteles, las basas de las columnas y los ornatos de puertas y ventanas son de piedra de «martelilla», de grano fino, vistosa y dócil a la labor; mientras que el zócalo es de mármol negro de Tarifa, ejecutándose lo demás en estuco (Plano V).

La misma R.O. que aprobaba el proyecto general de San Carlos, autorizaba el particular de su Iglesia parroquial, resolviéndose que tuviese por advocación la de la Purísima Concepción de Nuestra Señora, como patrona tutelar de los reinos de España y de las Indias. El bailío Valdés prevenía a las autoridades de Marina del Departamento que se asentara solemnemente su primera piedra, que habría de significarse como el cimiento y origen de la nueva población. El ceremonioso acto tuvo lugar el domingo 2 de julio del mismo año de 1786. La primera piedra era de fina calidad, blanca y labrada con esmero. Con forma de paralepípedo rectangular, en sus cuatro caras verticales se esculpieron un sol, una luna, una rosa y una azucena. En una de sus bases se efectuó un hueco hecho a cincel, destinado a contener un tubo de cristal revestido exteriormente con una funda de plomo. En el interior de la vasija de cristal se depositaron un plano de la nueva población con los terrenos adyacentes, una vista de la bahía sobre vitela, un Estado General de la Armada del mismo año, y tres monedas, una de oro, la segunda de plata, y la tercera de bronce. La boca del frasco se tapó con betún, y la funda de plomo se estan̄ó.

En lo relativo al proceso constructivo, se ha de señalar que los trabajos fueron llevados por administración oficial, al igual que ocurrió con el Cuartel de Batallones, sin darse la obra a asentistas. Cuando Antonio Ponz efectuó su visita en 1791, y el cuerpo de la iglesia se encontraba a nivel de las cornisas y metida la arquería de las naves laterales, propuso la moderación de la altura prevista para los campanarios y la supresión de "mezquindades de rematitos y perinolas»; sugerencias que fueron recogidas por el Marqués de Ureña. Éste, que se habia hecho cargo cuando el edificio contaba con una elevación general aproximada de 8 varas, sin alterar la planta ni la distribución interior, pretendió dejar 
el templo por su exterior «un poco más conforme a las reglas del buen gusto", criticando los campanarios, crecidos en demasía y algo macizos; la excesiva altura del tambor del domo y el embasamento de la linterna -advirtiendo que era doble en su elevación a lo que prescribian las reglas de Fontana-; la curvatura de la cúpula, poco distinguible; las grandes ménsulas de los balcones de la fachada; la ventana, con igual elemento sustentante, colocada sobre el arco principal del ingreso, sustituible por un simple tablero entrante a rellenar con un ornato alegórico o inscripción; y la excesiva estatuaria externa, que se podía limitar a dos ángeles mancebos sentados sobre los cabrios del frontón. En síntesis, pretendia apiramidar el todo, con vistas a producir un mejor efecto, y evitar adornos innecesarios que ofuscaran la hermosura de su fábrica.

En 1794 las obras se paralizaron casi por completo, disponiéndose en abril del año siguiente que se concluyera la capilla del sagrario para que sirviera de iglesia provisional, continuándose las actividades más imprescindibles en el resto del edificio para precaverlo de su deterioro. A finales de 1796, las relaciones mensuales de lo trabajado advierten acerca de la interrupción total de las labores. Y es, precisamente, a partir de estos momentos cuando se hace muy difícil conocer los hechos con exactitud, a causa de la carencia casi absoluta de documentación; si bien entonces el estado general de la Hacienda no permite deducir otra cosa que la inoperancia o el lentísimo y desesperante progreso de las faenas - paradójicamente, cuando la Marina militar de España ha llegado a ser una fabulosa fuerza de combate, compuesta por 76 navíos de línea, 51 fragatas, 9 corbetas, 10 jabeques, 30 bergantines, 6 paquebotes y 16 urcas: en total, 198 buques ${ }^{14}$. Días antes del fallecimiento del Marqués de Ureña, el 28 de octubre de 1806, el interventor de las obras de la nueva población abonaba la suma de 5.476 reales de vellón para el pago de atenciones diversas, entre las que se encontraban el abono de los jornales invertidos en desmantelar los andamios del templo, cuando estaba a la altura de la cornisa general, sin llegarse a levantar los campanarios ni a cubrir la nave central.

Durante la primera mitad del siglo xIX el recinto llegó a ser un depósito de inmundicias, formado por escombros, basuras, plantas silvestres e, incluso, cadáveres del hospital vecino. El 10 de octubre de 1850, siendo ministro de Marina el Marqués de Molins, una Real Orden destinó

14 En aquel momento, Inglaterra poseía de 200 a 220 navíos, 250 fragatas y unos 500 buques menores, mientras que Francia, tras el saqueo de Tolón, el combate de Quessant, y las enormes atenciones al ejército de tierra, sólo contaba de 30 a 35 navíos y otras tantas fragatas. 
el inconcluso edificio a Panteón de llustres Marinos, habilitándose como capilla para los cultos una de las sacristías y repartiéndose por las naves, sin orden ni concierto, monumentos funerarios. En la presente centuria se realizaron obras diversas de mantenimiento (limpieza, deshollinado, revoques, reparación de puertas y claraboyas, colocación de vidrieras...), proyectadas por el ramo de ingenieros de La Carraca. No sería hasta diciembre de 1942 cuando comenzara el proceso, controlado por la Dirección de Construcciones e Industrias Navales Militares del Ministerio de Marina, y finalizado en 1958, que ha completado el aspecto actual, acometiéndose las obras de cubrir la nave central, levantar la cúpula sobre el crucero, realizar el presbiterio y el altar mayor con su retablo, dar entrada también al edificio por el testero $y$, aprovechándose la gran rotonda del fondo, erigir un monumento del mayor interés, alegórico homenaje a quienes han encontrado en el mar su última morada; quedando configurada la construcción con el doble carácter de iglesia y panteón. 


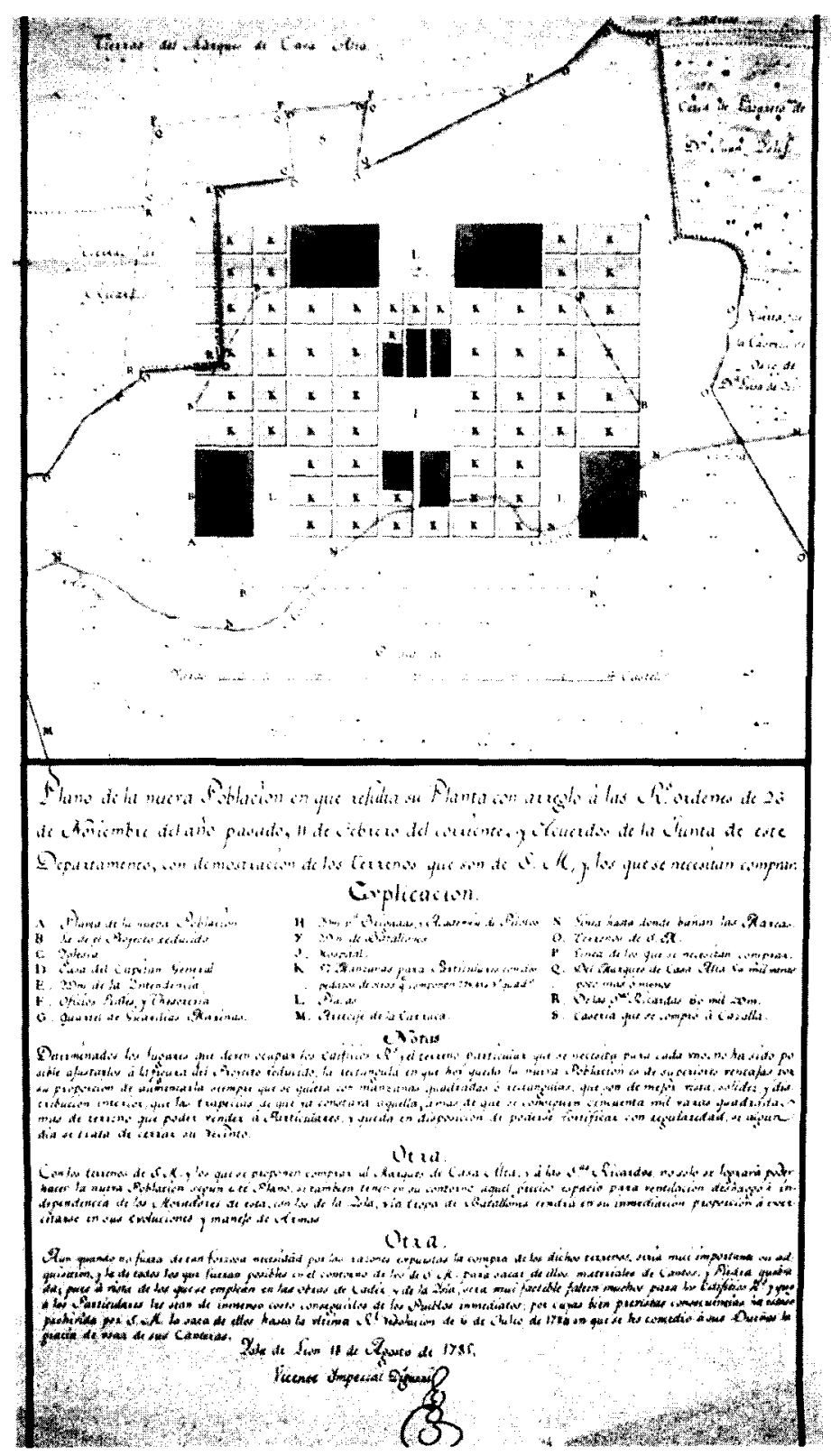

PLANO I. Nueva Población para la Armada en terrenos de la Isla de León. Vicente Imperial Digueri, 1785. Museo Naval, Madrid. (En negro, las manzanas y parcelas para los edificios reales; en gris, para los particulares). 
Vicente Ignacio Imperial Digueri y Trejo: ingeniero militar, marino...

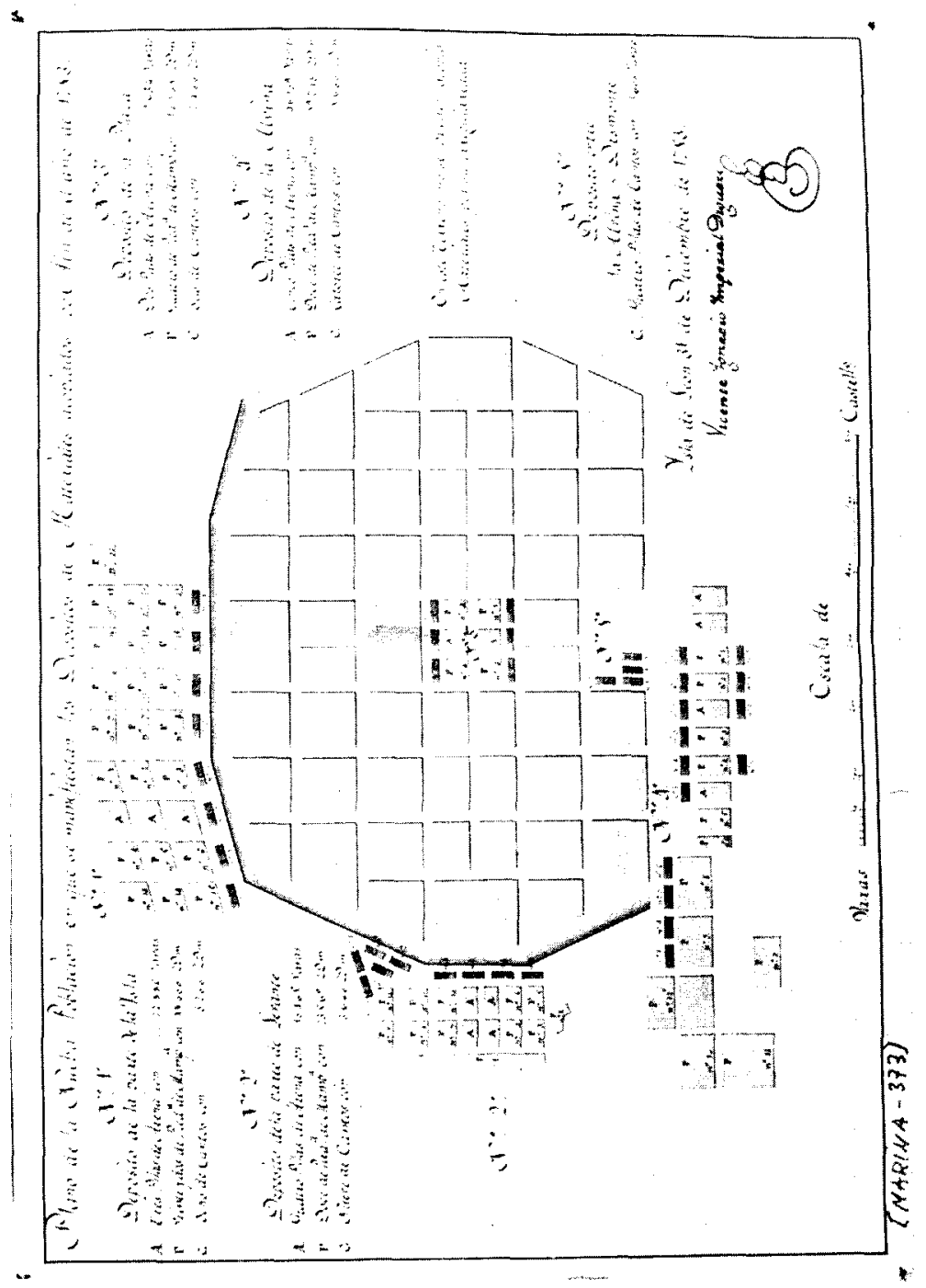

อุ क

$\stackrel{2}{2}$

8 :

密

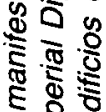

है

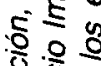

$\frac{8}{8}$

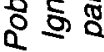

ช ํำ

之ั

ब 2 है

एहิ

: कू

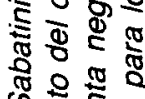

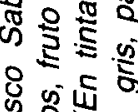

o

赵

ᄂ

8

क क

웡

ลำ

08
$=80$

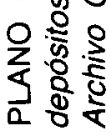




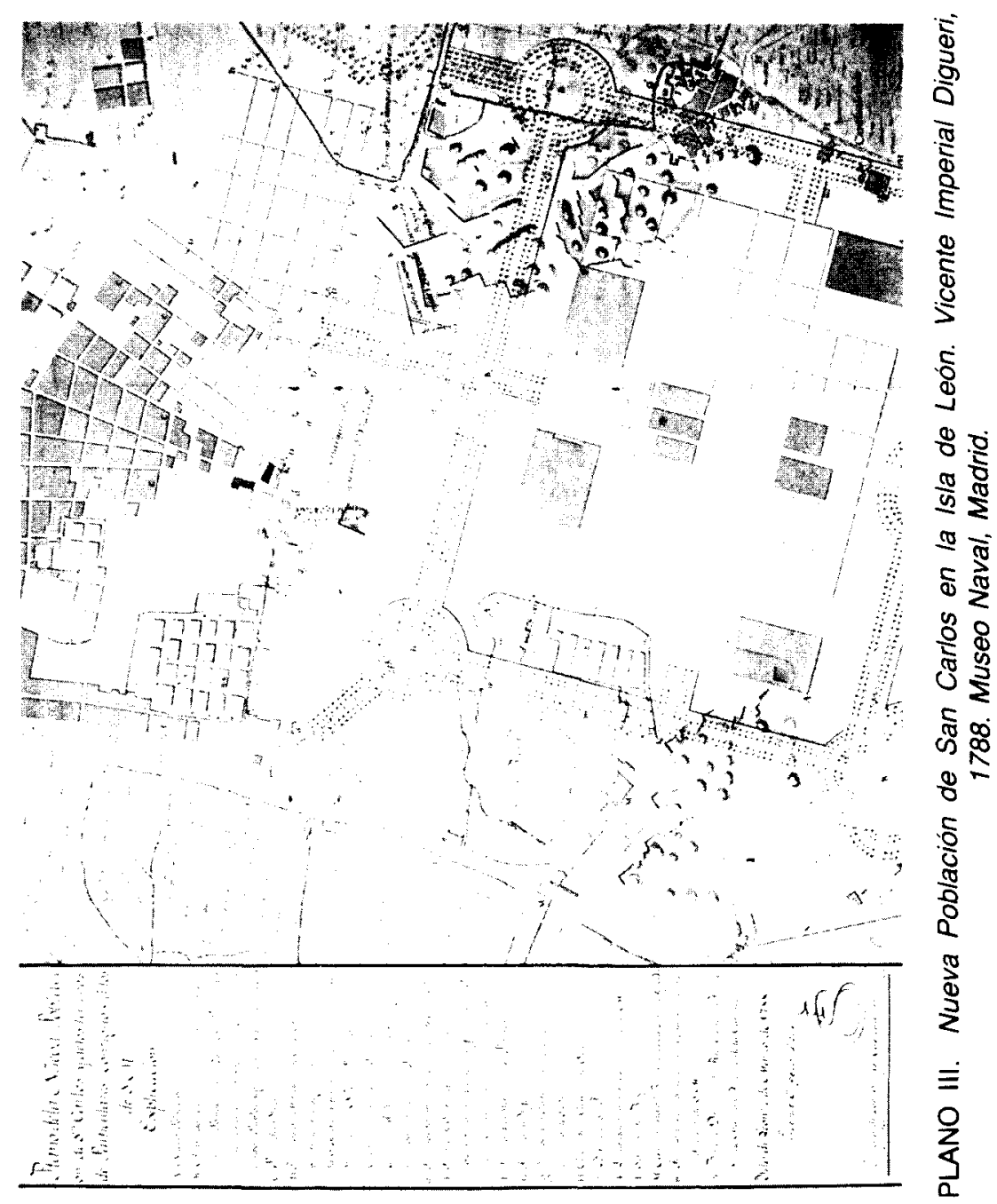


Vicente Ignacio Imperial Digueri y Trejo: ingeniero militar, marino...

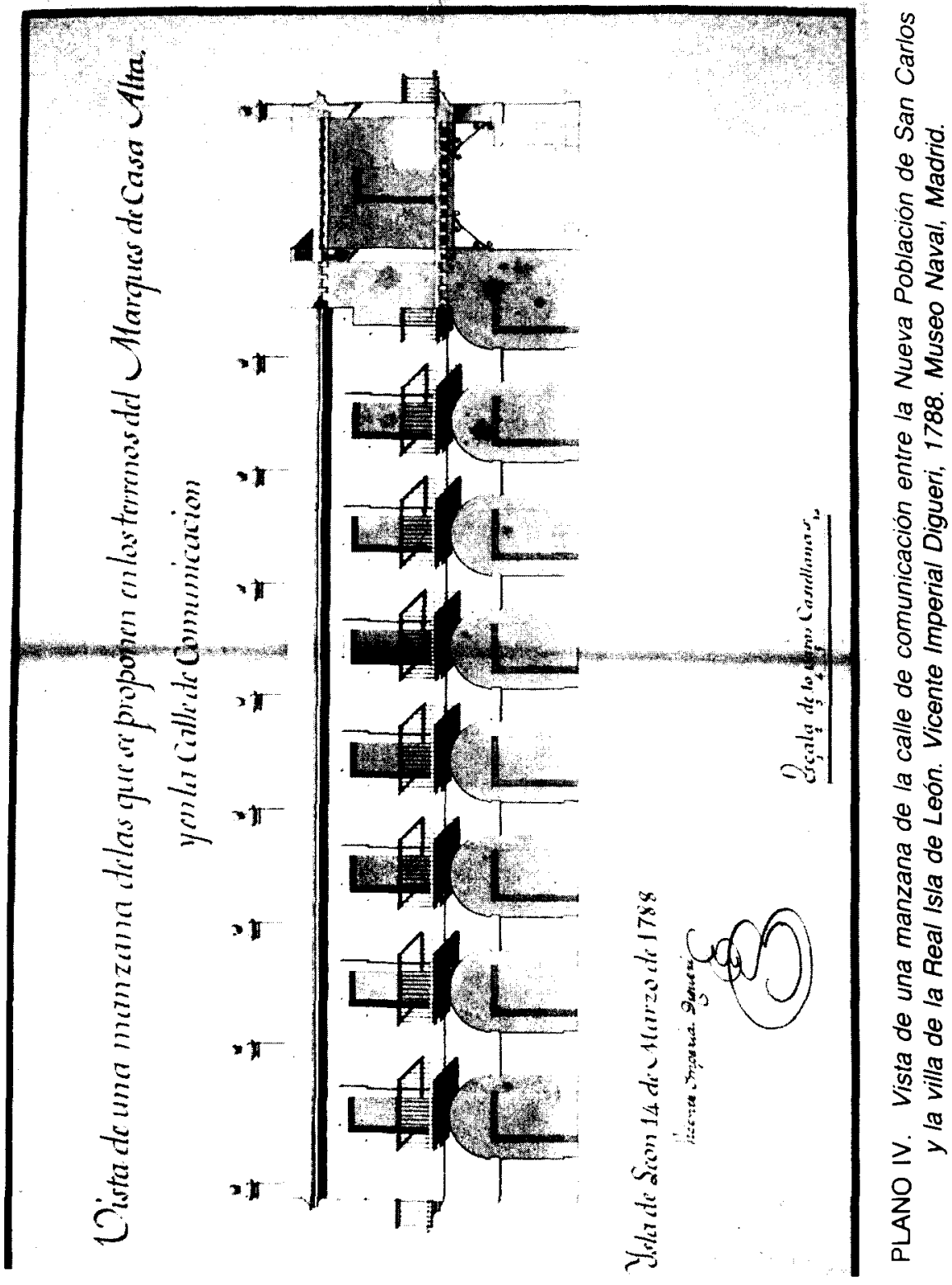



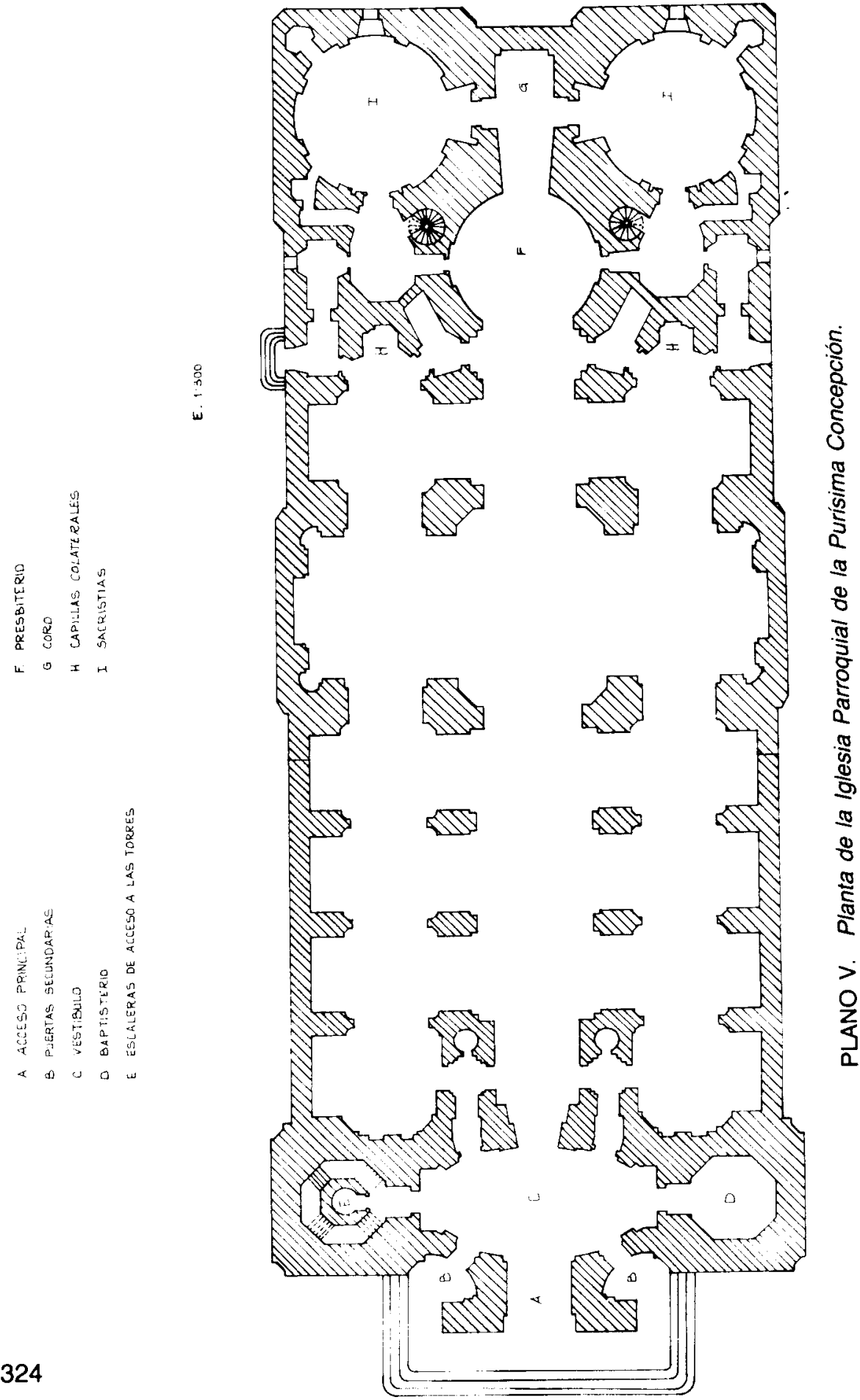
Vicente Ignacio Imperial Digueri y Trejo: ingeniero militar, marino...
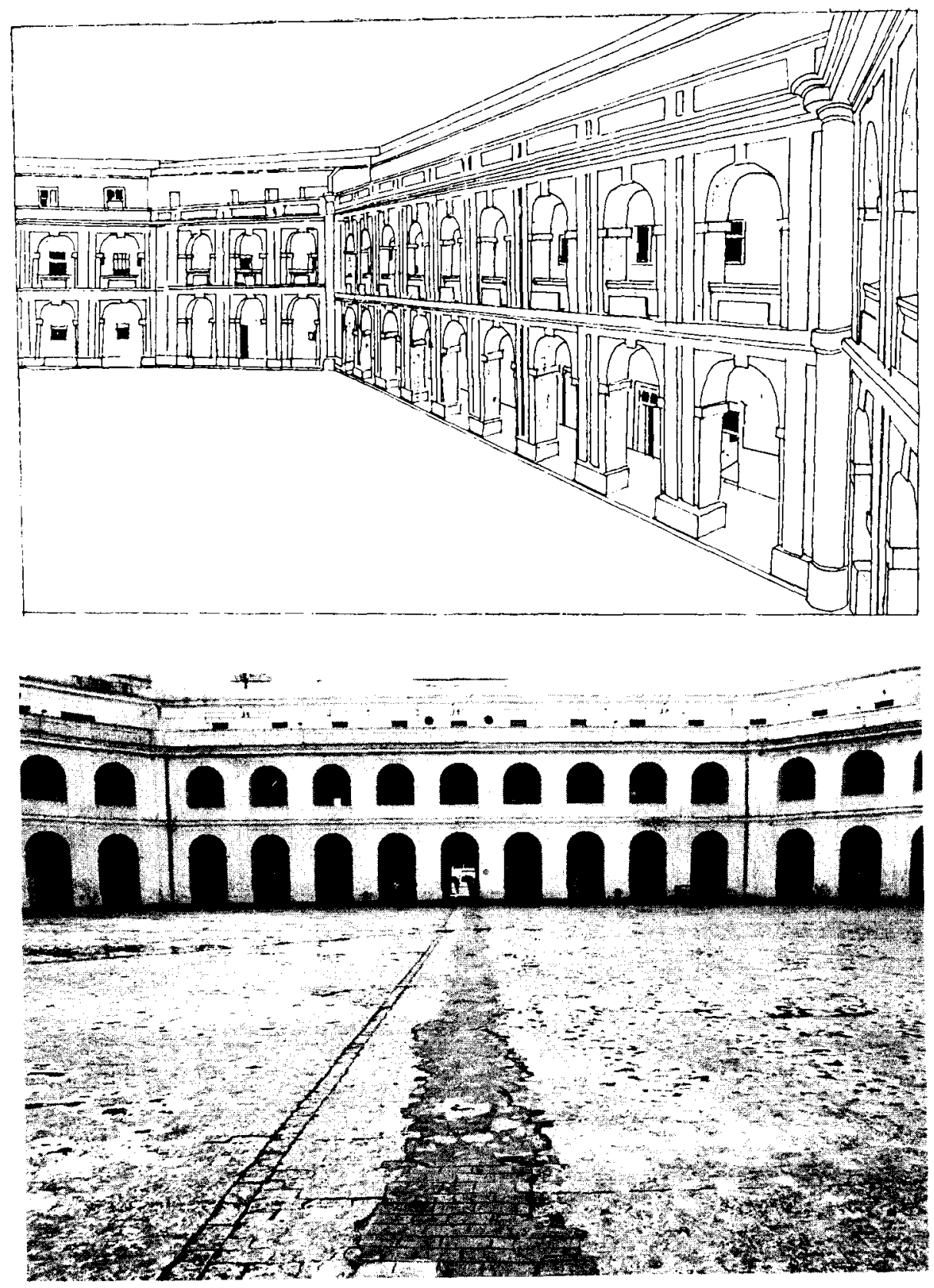

Patio del Cuartel de Batallones de la Nueva. Población de San Carlos. 
JUAN TORREJON CHAVES

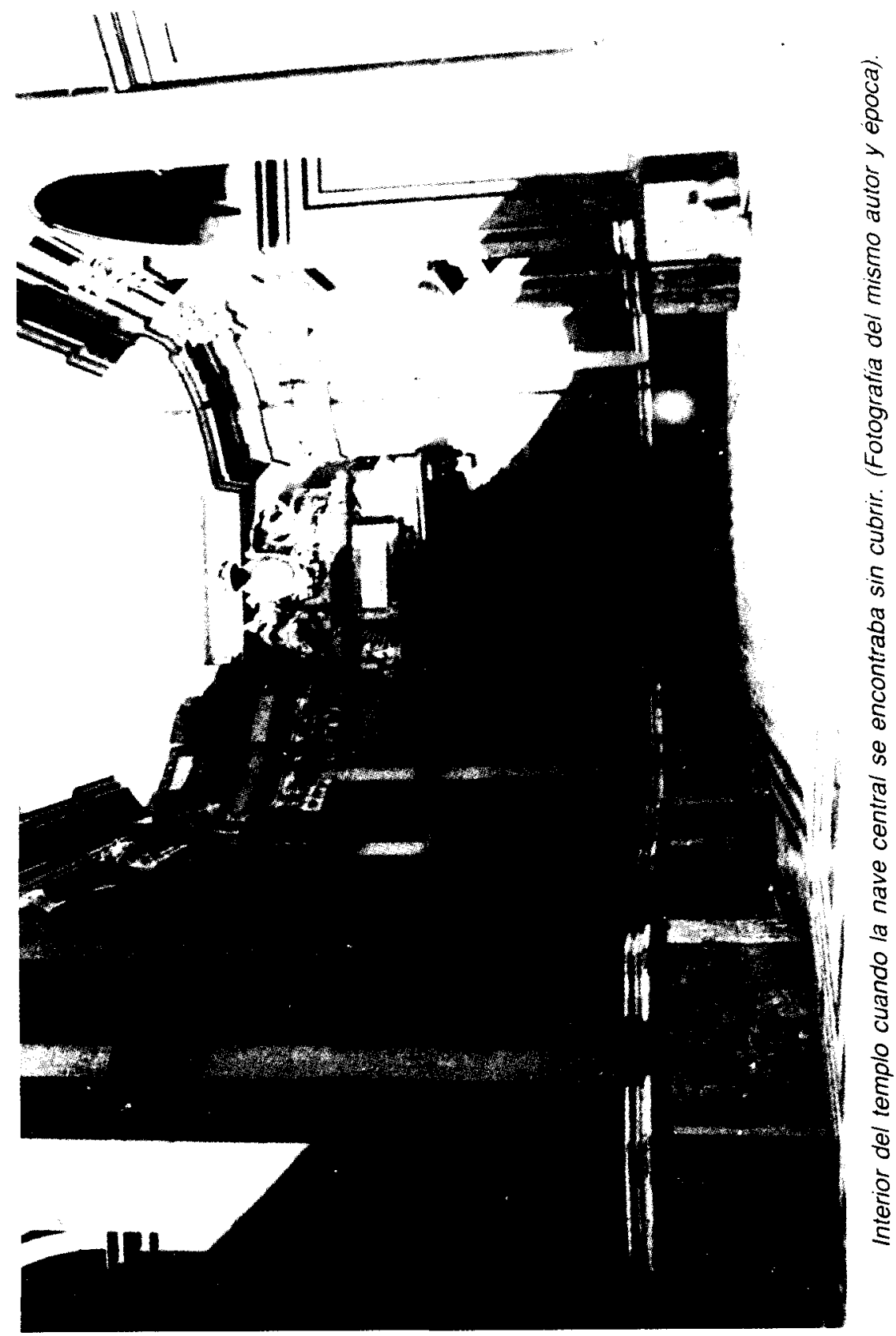


Vicente Ignacio Imperial Digueri y Trejo: ingeniero militar, marino...

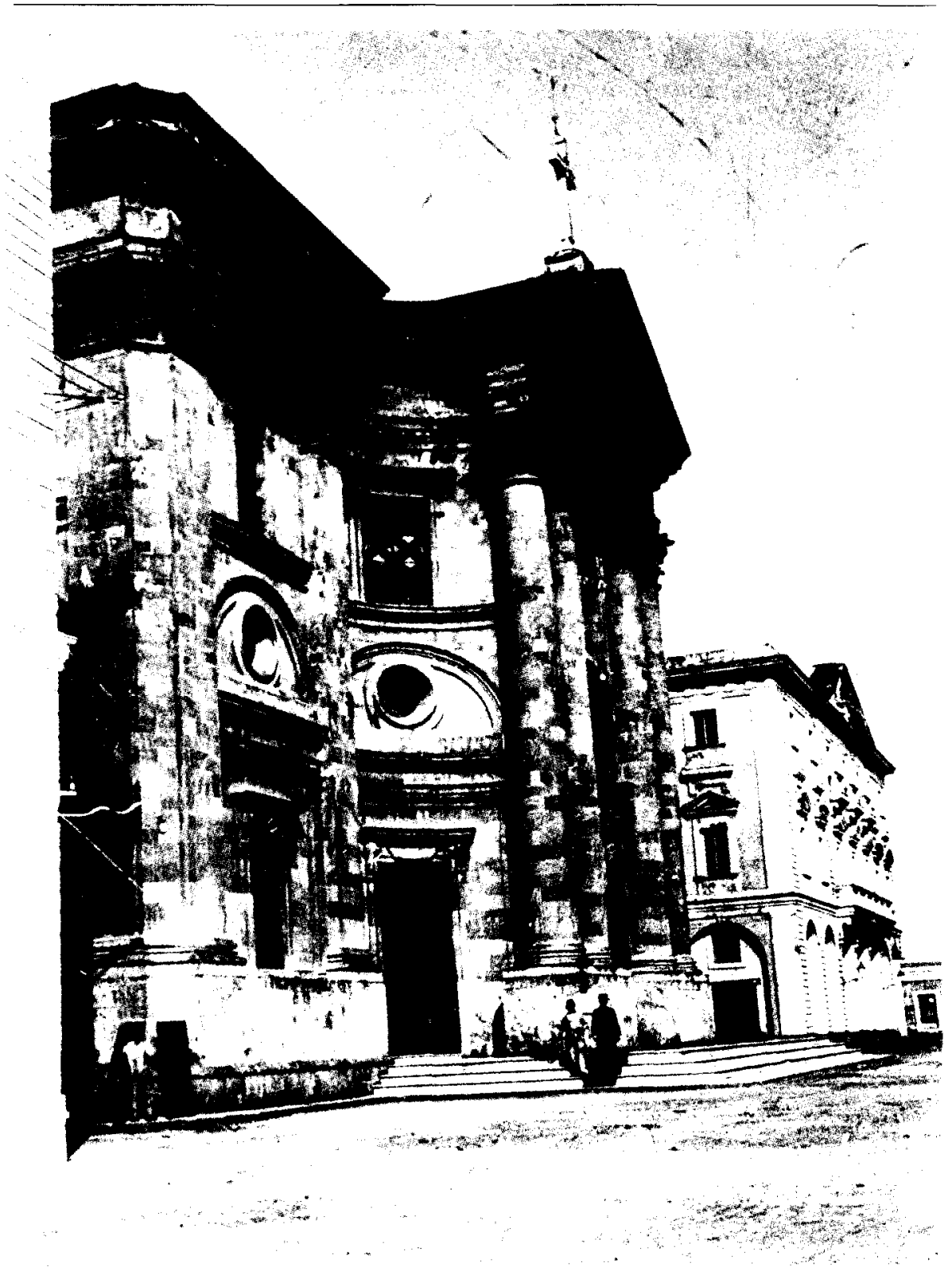

Fachada de la Iglesia Parroquial de la Nueva Población de San Carlos, actual Panteón de Marinos Ilustres. Al fondo, la Casa del Capitán General del Departamento, proyectada y levantada por el Marqués de Ureña, hoy desaparecida. (La fotografia fue tomada hacia 1910 por el corredor de comercio gaditano Ramón Muñoz). 